\title{
Association of complement alleles C4AQ0 and C4B5 with rheumatoid arthritis in Koreans
}

Myoung Hee Park, Myoung-Don Oh, Yeong Wook Song, Hyun Joo Pai, Fujio Takeuchi, Katsushi Tokunaga, Gi Hyun Hong, Kyoung Sook Park

\begin{abstract}
Objective-To investigate the association of complement $\mathrm{C} 4$ allotypes with rheumatoid arthritis in Koreans.

Methods-65 rheumatoid arthritis patients and 255 controls were typed for $\mathrm{C} 4$ allotypes and HLA-A, B, C, DR, and DQ antigens.

Results-The frequencies of C4AQ0 $\mathbf{3 2 . 3 \%}$ $v 14.9 \%, P<0.005)$ and C4B5 (29.2\% $v 12.2 \%$, $P<0.005)$ were significantly increased in rheumatoid arthritis patients compared with healthy control subjects. Among rheumatoid patients, the frequency of C4AQ0 was significantly increased in both the rheumatoid factor (RF) positive (27.3\%) and the RF negative (66.7\%) subgroups. The frequencies of $\mathrm{C} 4 \mathrm{~B} 5$ and HLA-DR4 were significantly increased only in RF positive subgroup. C4B5 was strongly associated with HLA-DR4, whereas C4AQ0 did not show association with DR4.

Conclusions-In Koreans, C4AQ0 and C4B5 are associated with susceptibility to rheumatoid arthritis, as in the Japanese. C4B5 is strongly associated with HLADR4. C4AQ0 is considered to be a DR4 independent risk factor, and a disease susceptibility allele in linkage disequilibrium with C4AQ0 is suggested in Korean patients with rheumatoid arthritis.
\end{abstract}

(Ann Rheum Dis 1996;55:776-778)

The association of rheumatoid arthritis with HLA-DR4 is well established, and confirmed in many ethnic groups. ${ }^{1}$ It remains unclear, however, whether DR4 itself, or a susceptibility gene closely linked to DR4, is important for the occurrence of rheumatoid arthritis. In this context, there has been interest in the class III region of the major histocompatibility complex (MHC), which contains the genes coding for the second component of complement (C2), factor $B(B F)$, and the fourth component of complement (C4A and C4B). However, reports on the association between rheumatoid arthritis and allotypes of $\mathrm{BF}, \mathrm{C} 4 \mathrm{~A}$, and $\mathrm{C} 4 \mathrm{~B}$ have been controversial. ${ }^{2-11}$

Recently the association of complement alleles $C 4 A Q 0$ and $C 4 B 5$ with rheumatoid arthritis has been reported in the Japanese. ${ }^{9}$ This finding has not been confirmed in other ethnic groups. The genetic background of Koreans is most close to that of the Japanese among east Asian ethnic groups from the point of view of HLA genes and haplotypes. ${ }^{12}$ Therefore, we decided to investigate the association of C4 allotypes with rheumatoid arthritis in Korean patients to gain a better understanding of the immunogenetics of the disease. For the study of HLA class I and II allelic associations with rheumatoid arthritis in Koreans, HLA-A, B, C, $D R$, and $D Q$ antigens were also examined in rheumatoid patients and controls.

\section{Methods}

PATIENTS

Blood specimens were obtained from 65 randomly selected Korean patients with rheumatoid arthritis, diagnosed according to the American Rheumatism Association criteria. ${ }^{13}$ There were 10 men and 55 women. Mean age at the time of the study was 47 (range 19 to 68 ) and mean disease duration was 8.4 years (range 1 to 30 years). Rheumatoid factor (RF) was positive in 55 patients, using the latex test. Rheumatoid nodules were present in four patients, and extra-articular signs other than rheumatoid nodules in six patients, including one case of Felty syndrome. Clinical stages were II in 30 patients, III in 30 patients, and IV in one patient. Controls were 255 healthy Koreans, including 156 parents from family study material for the analysis of extended HLA haplotypes.

\section{C4 TYPING}

EDTA treated plasma samples were used for C4 typing and the procedure was essentially the same as previously described. ' In brief, EDTA-plasma samples pretreated with carboxypeptidase $B$ and neuraminidase were typed for $\mathrm{C} 4 \mathrm{~A}$ and $\mathrm{C} 4 \mathrm{~B}$ allotypes using high voltage agarose gel electrophoresis followed by immunofixation. C4B bands were further detected by a C4 dependent haemolytic overlay method. The nomenclature (1990) used for the $\mathrm{C} 4$ allotypes was according to Mauff et al. ${ }^{14}$

\section{HLA TYPING}

Typing for HLA-A, B, C, DR, and DQ antigens was carried out by standard microcytotoxicity test using $\mathrm{T}$ and $\mathrm{B}$ lymphocytes separated by nylon wool column.

\section{STATISTICAL ANALYSIS}

The $\chi^{2}$ test or Fisher exact test was used to compare findings for rheumatoid arthritis patients with those for control subjects. Odds ratios and $95 \%$ confidence limits were calculated using the PC SAS program. 
Table 1 Distribution of $C 4 A$ and $C 4 B$ allotypes in Korean patients with rheumatoid arthritis $(R A)$ and in control subjects

\begin{tabular}{lllll}
\hline & $\begin{array}{l}\text { Controls } \\
(n=255)\end{array}$ & $\begin{array}{l}R A \text { patients } \\
(n=65)\end{array}$ & $\begin{array}{l}\text { Odds ratios (95\% confidence } \\
\text { limits) }\end{array}$ & $P$ \\
\hline C4AQ0† & $38(14.9)$ & $21(32.3)$ & $2.7(1.5-5.1)$ & $<0.005$ \\
C4A3 & $221(86.7)$ & $53(81.5)$ & $0.7(0.3-1.4)$ & NS \\
C4A4 & $70(27.5)$ & $21(32.3)$ & $1.3(0.7-2.3)$ & NS \\
C4AR† & $25(9.8)$ & $3(4.6)$ & $0.5(0.1-1.5)$ & NS \\
C4BQ0† & $11(4.3)$ & $4(6.2)$ & $1.5(0.5-4.7)$ & $<0.05$ \\
C4B1 & $226(88.6)$ & $49(75.4)$ & $0.4(0.2-0.8)$ & NS \\
C4B2 & $99(38.8)$ & $28(43.1)$ & $1.2(0.7-2.1)$ & $<0.005$ \\
C4B5 & $32(12.6)$ & $19(29.2)$ & $2.9(1.5-5.5)$ & NS \\
C4BR† & $5(2.0)$ & $0(0)$ & $0.8(0.1-6.8)$ & $<0.01$ \\
C4AQ0/ & $1(0.4)$ & $4(6.2)$ & $16.7(1.8-151.7)$ & \\
C4B5 & & & &
\end{tabular}

^ Percent shown in parentheses.

$+\mathrm{C} 4 \mathrm{AQ} 0$ and $\mathrm{C} 4 \mathrm{BQ} 0$ are all probable heterozygous allotypes except homozygous C4AQ0 in one control and one RA patient, and homozygous C4BQ0 in two RA patients. C4AR and C4BR are rare alleles.

$\ddagger$ NS, not significant.
$(60.7 \%$ v 36.9\%, P <0.001, OR 2.6) (table 2). Association of C4AQ0 and C4B5 with HLA-DR4 was analysed in rheumatoid patients and controls (table 3). C4AQ0 did not show an association with HLA-DR4 and there was no significant difference in the frequency of C4AQ0 between DR4 negative and DR4 positive rheumatoid patients. The frequency of C4AQ0 was increased in DR4 negative patients compared with DR4 negative controls $(P<0.005)$. C4B5 was strongly associated with HLA-DR4 in both control and rheumatoid patient groups. The frequency of C4B5 allotype was significantly higher in DR4 positive than in DR4 negative individuals in both control and patient groups $(\mathrm{P}<0.001, \mathrm{P}$ $<0.005$ respectively). DR4 positive rheumatoid patients showed increased frequency of C4B5 compared with DR4 positive controls ( $P$ $<0.05)$.

HLA haplotypes carrying C4AQ0 and C4B5 were studied in 156 controls derived from family study material. C4B5 showed a strong linkage disequilibrium with HLA-B54 or B59, DR4, DQ4, and C4A3 and the most frequent extended haplotype was HLA-B54 or B59; BFS; C4A3; C4B5; DR4; DQ4 (13/22 C4B5 positive haplotypes). This allelic association was also that most commonly observed in C4B5 positive rheumatoid arthritis patients (8/19), although BF was not studied in the patient group. On the other hand, C4AQ0 showed a strong linkage disequilibrium with HLA-A33, B58, DR13, and DQ1 in healthy controls, and the most frequent extended haplotype carrying $\mathrm{C} 4 \mathrm{AQ} 0$ was $\mathrm{A} 33$; $\mathrm{Cw} 10$; $\mathrm{B} 58$; BFF; C4AQ0; C4B1; DR13; DQ1 (6/15 C4AQ0 positive haplotypes). However, in rheumatoid patients, this allelic association was not observed and $\mathrm{C} 4 \mathrm{AQ} 0$ did not show a significant association with any HLA class I or class II allele. rheumatoid arthritis patients, whereas that of C4B5 and HLA-DR4 was significantly increased only in the RF positive subgroup. The frequency of C4AQ0 was higher in the RF negative than in the RF positive subgroup $(66.7 \% v 27.3 \%, P<0.05)$. Other clinical findings-such as gender, disease duration, clinical stage, presence of family history, rheumatoid nodule, or other extra-articular signswere not associated with $\mathrm{C} 4$ allotypes, nor were the inflammatory variables.

ASSOCIATION OF C4AQ0 AND C4B5 WITH HLA The frequency of HLA-DR4 was increased in rheumatoid patients compared with controls

\section{Discussion}

In our study, the frequencies of C4AQ0 and C4B5 allotypes were significantly increased in Korean patients with rheumatoid arthritis. This finding was also observed in a previous study of Japanese patients with rheumatoid arthritis, ${ }^{9}$ but in none of the studies of other ethnic groups. ${ }^{2-81011}$ Thus far, a limited number of studies on the association between complement allotypes and rheumatoid arthritis has been reported in populations from the United States and Europe, and the results have

Table 2 Relations between presence of rheumatoid factor (RF), and complement C4AQ0, C4B5 and HLA-DR4 in Korean patients with rheumatoid arthritis $(R A)$

\begin{tabular}{|c|c|c|c|c|c|c|c|c|}
\hline & \multirow[b]{2}{*}{$\begin{array}{l}\text { Controls* } \\
(n=255)\end{array}$} & \multicolumn{3}{|c|}{$R A$ patients* } & \multicolumn{4}{|c|}{ Odds ratios ( $95 \%$ confidence limits) } \\
\hline & & $\begin{array}{l}\text { Total } \\
(n=65)\end{array}$ & $\begin{array}{l}R F(+) \\
(n=55)\end{array}$ & $\begin{array}{l}R F(-) \\
(n=9)\end{array}$ & $P^{a}$ & $P^{b}$ & $P$ & $P^{d}$ \\
\hline C4AQ0 & $38(14.9)$ & $21(32.3)$ & $15(27.3)$ & $6(66.7)$ & $\begin{array}{l}2.7(1.5-5.1) \\
\mathrm{P}<0.005\end{array}$ & $\begin{array}{l}2.1(1.1-4.3) \\
P<0.05\end{array}$ & $\begin{array}{l}11.4(2.7-47.6) \\
P<0.001\end{array}$ & $\begin{array}{l}0.2(0.0-0.8) \\
P<0.05\end{array}$ \\
\hline C4B5 & $32(12.6)$ & $19(29.2)$ & $18(32.7)$ & $1(11.1)$ & $2.9(1.5-5.5)$ & $3.4(1.7-6.7)$ & $0.9(0.1-7.2)$ & $\begin{array}{l}3.9 \\
(0.5-33.5)\end{array}$ \\
\hline HLA-DR4† & $94(36.9)$ & $37(60.7)$ & $32(62.7)$ & $4(44.4)$ & $\begin{array}{l}P<0.005 \\
2.6(1.5-4.7) \\
P<0.001\end{array}$ & $\begin{array}{l}P<0.001 \\
2.9(1.5-5.4) \\
P<0.001\end{array}$ & $\begin{array}{l}\text { NS } \ddagger \\
1.4(0.4-5.2) \\
\text { NS }\end{array}$ & $\begin{array}{l}\text { NS } \\
2.1(0.5-8.8) \\
\text { NS }\end{array}$ \\
\hline
\end{tabular}

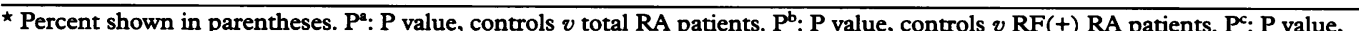
controls $v$ RF $(-)$ RA patients. $P^{d}: P$ value, $R F(-) R A$ patients $v$ RF $(+) R A$ patients. + HLA-DR was typed in $61 \mathrm{RA}$ patients: 51 $R F(+), 9(R F(-)$. $¥ N S$, not significant. 
Table 3 Association of C4AQO and C4B5 with HLA-DR4 in Korean patients with rheumatoid arthritis (RA) and in control subjects

\begin{tabular}{|c|c|c|c|c|c|c|c|c|}
\hline & \multicolumn{2}{|c|}{ Controls* $(n=255)$} & \multicolumn{2}{|c|}{$R A$ patients* } & \multicolumn{4}{|c|}{ Odds ratios ( $95 \%$ confidence limits) } \\
\hline & $\begin{array}{l}D R 4(-) \\
(n=161)\end{array}$ & $\begin{array}{l}D R 4(+) \\
(n=94)\end{array}$ & $\begin{array}{l}D R 4(-) \\
(n=24)\end{array}$ & $\begin{array}{l}D R 4(+) \\
(n=37)\end{array}$ & $P^{a}$ & $P^{b}$ & $p^{c}$ & $p^{d}$ \\
\hline C4AQ0 & $19(11.8)$ & $19(20.2)$ & $9(37.5)$ & $12(32.4)$ & $1.9(1.0-3.8)$ & $\begin{array}{l}4.5 \\
(1.7-11.7)\end{array}$ & $1.9(0.8-4.5)$ & $0.8(0.3-2.4)$ \\
\hline C4B5 & $6(3.7)$ & $25(26.6)$ & $2(8.3)$ & $17(45.9)$ & $\begin{array}{l}\text { NSt } \\
9.4(3.7-23.8) \\
P<0.001\end{array}$ & $\begin{array}{l}\mathrm{P}<0.005 \\
2.4 \\
(0.5-12.4) \\
\text { NS }\end{array}$ & $\begin{array}{l}\text { NS } \\
2.4(1.1-5.2) \\
P<0.05\end{array}$ & $\begin{array}{l}\text { NS } \\
9.4 \\
(1.9-45.6) \\
P<0.005\end{array}$ \\
\hline
\end{tabular}

‡ Percent shown in parentheses. $\mathrm{P}^{\mathrm{a}}: \mathrm{P}$ value, DR4(-) controls $v$ DR4(+) controls. $\mathrm{P}^{\mathrm{b}}: \mathrm{P}$ value, DR4(-) controls $v$ DR4(-) RA patients. $\mathrm{P}^{c}:$ P value, DR4(+) controls $v$ DR4(+) RA patients. $P^{d}:$ P value, DR4(-) RA patients $v$ DR4(+) RA patients. $\dagger$ NS, not significant.

been controversial..$^{2-8} 10^{11}$ Association between allotypes of $\mathrm{BFS},{ }^{4-6} \mathrm{C} 4 \mathrm{~B} 3,{ }^{238} \mathrm{C} 4 \mathrm{~A} 4,{ }^{11} \mathrm{C} 4$ null alleles, ${ }^{10}$ and rheumatoid arthritis has been reported.

In our study, we found that C4B5 was strongly associated with HLA-DR4 in both control and rheumatoid arthritis patient groups. DR4 positive rheumatoid arthritis patients showed higher frequency of C4B5 than DR4 positive controls (table 3), probably because of the association of C4B5 with certain subtypes of DR4 related to rheumatoid arthritis susceptibility in Koreans (DRB1 ${ }^{\star} 0405$, unpublished observation). In comparison, C4AQ0 was not associated with HLA-DR4, and C4AQ0 was considered to be a DR4 independent rheumatoid arthritis susceptibility factor (table 3 ).

We found an interesting relation between $R F$ and complement C4AQ0, C4B5, and HLA-DR4 in rheumatoid patients (table 2). The frequencies of C4B5 and HLA-DR4 were significantly increased only in the RF positive subgroup. The frequency of C4AQ0 was significantly increased in both the RF positive subgroup $(27.3 \%)$ and the $R F$ negative subgroup $(66.7 \%)$ and more markedly increased in the latter. Although the number of RF negative patients was rather small in our study, this finding suggests that C4AQ0 is an independent risk factor determining rheumatoid arthritis susceptibility in Koreans, and might play an important role, especially in RF negative patients.

Thus far, reported positive associations of complement allotypes with rheumatoid arthritis have mostly involved certain haplotypes bearing both HLA-DR4 and C4B3 or BFS. ${ }^{23578}$ In the present study, C4AQ0 was not associated with HLA-DR4, and a disease susceptibility allele in linkage disequilibrium with C4AQ0 is suggested in Korean patients with rheumatoid arthritis. It is interesting that C4AQ0 confers disease susceptibility to rheumatoid arthritis in the Japanese ${ }^{9}$ and Koreans, who have very similar genetic backgrounds in terms of their HLA and C4 types. ${ }^{12}{ }^{15}$ Hillarby et al ${ }^{10}$ reported associations of C4AQ0 with vasculitis and C4BQ0 with Felty syndrome among DR4 positive rheumatoid arthritis patients. We could not find such associations in the present study, in which the numbers of patients with extra-articular disease were rather small.

1 Tiwari JL, Terasaki PI. HLA and disease associations. New York: Springer-Verlag, 1985: 55-61.

2 McCluskey J, Kay PH, Dawkins RL, Komori K, Christiansen FT, McCann VJ. Association of specific MHC supratypes with rheumatoid arthritis and insulindependent diabetes mellitus. Disease Markers 1983;1:197212.

3 Raum D, Awdeh Z, Glass D, Kammer G, Khan MA, Coblyn JS, et al. Extended haplotypes of chromosome 6 in adult rheumatoid arthritis. Arthritis Rheum 1984;27:516-21.

4 Grennan DM, Dyer P, Dodds W, Read A, Haeney M, Clague $R$, et al. Clinical and immunogenetic studies in Clague $R$, et al. Clinical and immunogenetic studies in
multicase rheumatoid families. $Q \mathcal{Y}$ Med 1984;212:479-85.

5 Dahlqvist RS, Beckman G, Beckman L. Bf and C3 complement types in rheumatoid arthritis. Hum Hered 1985, 35:240-5

6 Dyer P, Grennan DM, Dodds W, Walton K, Read A, Klimiuk $\mathrm{P}$, et al. Genetic variants of properdin factor $\mathrm{B}(\mathrm{Bf})$ in rheumatoid arthritis. $\mathcal{F}$ Rheumatol 1985;12:456-7.

7 Sanders PA, Thomson W, Dyer PA, Grennan DM. Haplotypes bearing HLA-A, -B, and DR: Bf and C4 genes in rheumatoid arthritis families. Tissue Antigens 1988; 33:21-9.

8 Fielder AHL, Ollier W, Lord DK, Burley MW, Silman A, Awad J, et al. HLA class III haplotypes in multicase rheumatoid arthritis families. Hum Immunol 1989;25:75-85.

9 Takeuchi F, Mimori A, Matsuda K, Nakano K, Miyamoto $\mathrm{T}$, Matsuki $\mathrm{K}$, et al. Association of complement alleles C4AQ0 and C4B5 with rheumatoid arthritis in Japanese patients. Arthritis Rheum 1989;32:691-8.

10 Hillarby MC, Clarkson R, Grennan DM, Bate AS, Ollier W, Sanders PA, et al. Immunogenetic heterogeneity in rheumatoid disease as illustrated by different MHC associations (DQ, Dw and C4) in articular and extraarticular subsets. Br f Rheumatol 1991;30:5-9.

11 van Zeben D, Giphart MJ, Christiansen FT, Hoetjer M, Meyer ECM, Breedveld FC. Properdin factor B and complement factor $\mathrm{C} 4$ allotypes in rheumatoid arthritis: results of a follow-up study. Hum Immunol 1992;33:148-51.

12 Park MH, Juji T, Tokunaga K. HLA ethnic study of Japanese and Koreans. In: Tsuji K, Aizawa M, Sasazuki T, eds. HLA 1991, vol 1. New York: Oxford University Press, 1992:674-6.

13 Arnett FC, Edworthy SM, Bloch DA, McShane DJ, Fries JF, Cooper NS, et al. The American Rheumatism Association 1987 revised criteria for the classification of rheuma toid arthritis. Arthritis Rheum 1988;31:315-24.

14 Mauff G, Alper CA, Dawkins R, Doxiadis G, Giles CM, Hauptmann G, et al. C4 nomenclature statement (1990). Complement Inflamm 1990;7:261-8.

15 Tanaka H, Suzuki K, Mok JW, Park MH, An J, Sun Y, et al. Complement polymorphism in North-east Asian populaions. In: Tsuji K, Aizawa M, Sasazuki T, eds. HLA 1991, vol 1. New York: Oxford University Press, 1992:974-6. 